\title{
Kepemimpinan Etis Guru Dalam Pendidikan Karakter
}

\author{
Muhamad I. Suhifatullah \\ Magister Ilmu Administrasi Universitas Islam Syekh Yusuf \\ misuhifatullah@unis.ac.id \\ Mastur Thoyib \\ Magister Ilmu Administrasi Universitas Islam Syekh Yusuf \\ mthoyib@unis.ac.id \\ Jarnawi Afgani Dahlan \\ Pendidikan Matematika FPMIPA Universitas Pendidikan Indonesia \\ jarnawi@upi.edu
}

\begin{abstract}
This study aims to obtain data and information about the ethical leadership of teachers in character education in Tangerang City Middle School. Specifically to obtain data and information on four aspects of the ethical leadership of teachers in character education, with reference to transformational leadership, namely; 1) Idealized influence (Charismatic influence), 2) Inspirational motivation, 3) Intellectual stimulation, and 4) Individualized consideration (individual attention). This study uses a survey method with a quantitative descriptive variable approach. The population of this study were students from three State Junior High Schools in the city of Tangerang, which numbered 942 students, then the sample was taken by proportional random sampling obtained by the number of 90 students. The technique for data collection was used a questionnaire. Research data as follows; 1) The influence of teacher ideality for students, is at $60.30 \%$ including the moderate/sufficient category; 2) teacher's inspirational motivation for students, at $61.21 \%$ including the moderate / sufficient category; 3) teacher intellectual stimulation for students, at 59.22\% included in the moderate / sufficient category; 4) teacher's individual attention for students, is at 59.87\% including the category of moderate / sufficient. Then the accumulation of each of the aspects or indicators above obtained data that shows, that the ethical leadership of teachers in character education of students in Tangerang City Middle School is at 60\%, including the category of moderate or sufficient.
\end{abstract}

Keywords: Teacher Ethical Leadership, Character Education

\section{Article Info}

Received date: 8 April 2020

Revised date: 15 Juni 2020

Accepted date: 20 Juni 2020

\section{PENDAHULUAN}

Dalam pendidikan karakter di sekolah, guru merupakan tokoh kunci atau salah satu komponen utama (Anugraheni, 2017). Peran guru dalam pendidikan karakter di sekolah tidak dapat tergantikan oleh ketersediaan sarana belajar selengkap apapun dan seunggul apapun. Secara formal dalam UURI Nomor 14 Tahun 2005 Tentang Guru dan Dosen, pada Bab I Pasal 1 ayat 1 , diungkapkan bahwa: "guru 
adalah pendidik profesional dengan tugas utama mendidik, mengajar, membimbing, mengarahkan, melatih, menilai dan mengevaluasi peserta didik pada pendidikan anak usia dini, jalur pendidikan formal, pendidikan dasar, dan pendidikan menengah."

Keseluruhan peran guru di atas, secara tersirat memposisikan guru sebagai pemimpin dalam kegiatan pendidikan dan pembelajaran di sekolah. Guru adalah pemimpin di kelas maupun di luar kelas yang dapat mempengaruhi perilaku peserta didik dalam mencapai tujuantujuan pembelajaran, termasuk dalam pembentukan karakter peserta didik. Karena itu kepemimpinan guru dalam proses pendidikan di sekolah merupakan unsur penting yang harus mendapat perhatian serius, sehingga memberi dampak pada keefektifan dalam pembelajara (Leithwood, et. al., 2004). Namun demikian sampai saat ini peran guru sebagai pemimpin dalam proses pendidikan dan pembelajaran belum mendapat perhatian yang serius, indikasinya antara lain masih langkanya pembinaan aspek kepemimpinan guru, baik melalui kegiatan pelatihan maupun seminar yang diselenggarakan secara kedinasan.

Selama ini dalam pembicaraan mengenai kepemimpinan pendidikan, senantiasa hanya tertuju pada peran dan tugas seorang kepala sekolah. Pandangan seperti ini bisa dimengerti, karena hampir sebagian besar kegiatan penelitian, literatur dan berbagai seminar tentang kepemimpinan pendidikan lebih cenderung membicarakan tentang kepemimpinan kepala sekolah. Sedangkan terkait dengan kepemimpinan guru masih relatif terbatas. Menurut Nerlino (2020) "Findings reveal that both constructivist leadership theory and sociocultural theory provide insight into the past lukewarm success of teacher leadership implementation and guidance for future efforts in teacher leadership. Such efforts include reconceptualizing leadership in schools, redesigning development opportunities for teachers based on the link between leading and learning, capitalizing on collaboration between universities and schools, focusing on the mentorship of new teachers and developing teacher leadership in relation to well-studied local school cultures."

Temuan di atas menunjukkan, bahwa upaya mengimplementasikan kepemimpinan guru dalam proses pendidikan dan proses pembinaannya melalui kerjasama dengan berbagai pihak, belum menunjukkan praktek yang serius, masih suam-suam kuku. Padahal upaya-upaya pendidikan karakter di sekolah tidak akan berhasil tanpa keberadaan guru yang mampu berperan sebagai pemimpin. Karena upaya penanaman nilai-nilai moral tidak cukup hanya dengan menyampaikan kebenaran konsep (dengan mengatakan sebaiknya begini dan begitu dengan pengarahan), melainkan perlu ada kebenaran berjalan (nyata dapat dilihat) yang diperankan guru sebagai manusia model, sehingga dapat ditiru atau dicontoh. Terkait hal ini Ki Hajar Dewantara merumuskan tiga peran atau perilaku yang harus ditampilkan seorang pemimpin termasuk guru, yaitu; ing ngarso sung tulodo (di depan penjadi teladan), ing madyo mangun karso (di tengah-tengah harus mampu membangun semangat bawahan dalam berkarya atau bekerja), tut wuri handayani (di belakang harus mampu mendorong inisiatif dan percaya diri bawahan agar kreatif dalam mengatasi masalah).

Namun demikian belakangan ini dunia pendidikan di Indonesia dikejutkan oleh berbagai peristiwa di lingkungan sekolah yang mengindikasikan rendahnya kepemimpinan guru. Banyak perilaku guru yang tidak etis ditunjukkan dihadapan siswa. Hal ini alih-alih dapat menciptakan kenyamanan dalam belajar, nyatanya justru menimbulkan rasa takut dan atau kebencian peserta didik, sebagai akibat dari tindakan kekerasan atau perilaku tidak etis yang ditunjukkan oleh guru. 
Komisi Perlindungan Anak Indonesia (KPAI) menunjukkan, bahwa $87 \%$ lebih anak mengaku pernah mengalami kekerasan di lingkungan sekolah. Dari persentase itu, hampir $30 \%$ kekerasan dilakukan guru. Demikian pula hasil penelitian yang dilakukan oleh UNICEF (2006) di beberapa daerah di Indonesia menunjukkan, bahwa sekitar $80 \%$ kekerasan yang terjadi pada siswa dilakukan oleh guru. Di kalangan guru masih banyak yang memiliki keyakinan, bahwa cara kekerasan masih efektif untuk mengendalikan siswa. Padahal cara ini bisa menyebabkan trauma psikologis, atau siswa akan menyimpan dendam, makin kebal terhadap hukuman, dan cenderung melampiaskan kemarahan dan agresi terhadap siswa lain yang dianggap lemah. Lingkaran negatif ini jika terus berputar bisa melanggengkan budaya kekerasan di masyarakat.

Kondisi gap antara idealita dengan fakta di atas sangat memprihatinkan dan tentu tidak boleh dibiarkan, karena akan banyak menimbulkan mal praktek pendidikan terutama dalam upaya pendidikan karakter. Untuk itu perlu dicarikan akar masalahnya, sehingga dapat menjadi dasar tindakan bagi pihak terkait dalam melakukan perbaikan terhadap kondisi yang ada. Namun demikian sampai saat ini belum banyak penelitian pendidikan yang dapat mendeskripsikan kualitas kepemimpinan guru dalam proses pembelajaran. Nampaknya belum banyak yang menganggap aspek kepemimpinan guru sebagai hal yang signifikan dalam proses pendidikan di sekolah. Berbagai analisis kepemimpinan pendidikan lebih banyak menempatkan kepala sekolah sebagai objek kajiannya.

Temuan Moore, Latimer \& Villate (2016), mengungkapkan, bahwa : "There is a great need for teachers to take on leadership roles, informal and/or formal, for personal and professional growth and to improve schools. Internal and external impediments to teachers becoming leaders make the transitions from "just a teacher" to "teacher leader" difficult. Graduate teacher leader preparation programs need to assist teachers in developing confidence and professional identity as teacher leaders willing to be problem-solvers, change agents, and mentors who experience a high degree of professional and personal satisfaction". Intinya ada kebutuhan yang dirasakan guru untuk mengambil peran kepemimpinan baik secara formal maupun informal yang dapat meningkatkan kualitas diri dan profesinya terkait dengan upaya peningkatan mutu pendidikan di sekolah. Namun hal itu seringkali mendapat hambatan atau kurang mendapat dukungan dari berbagai pihak terkait, sehingga guru hanyalah seorang guru dan bukan seorang pemimpin.

Padahal menurut Harris \& Jones (2019), bahwa: "There seem to be three key_dimensions of teacher leadership, supported by the literature that are worth considering in the broader context of educational change. Firstly, the importance of teacher leadership as influence rather than a role or a formal responsibility. Secondly, the idea of teacher leadership as action going beyond their formally assigned classroom roles to share practice and initiate changes. Thirdly, developing pedagogical excellence within their classroom and beyond to influence the practice of others".

Tiga hal peran kepemimpinan guru di atas sangat penting bagi upaya pengembangan sekolah dan mutu pendidikan. Karena itu perlu ada upaya-upaya penelitian dan pembinaan kepemimpinan guru yang dapat meningkatkan kualitas diri dan profesinya secara berkesinambungan. Atas dasar itu dipandang penting untuk mendeskripsikan kepemimpinan guru khususnya terkait dengan perilaku etisnya secara akurat melalui penelitian. Diharapkan dengan terpetakan tingkat kualitas kepemimpinan etis guru atau moral guru di sekolah, dapat menjadi dasar untuk merekomendasikan program pembinaan 
kepemimpinan guru dalam meningkatkan kualitas pendidikan karakter peserta didik.

\section{METODE PENELITIAN}

Penelitian ini menggunakan metode survey dengan pendekatan kuantitatif deskriptif. Dalam konteks ini akan mendeskripsikan gejala atau fenomena saat ini yang berkaitan dengan kepemimpinan etis guru dalam pendidikan karakter di sekolah, berdasarkan pada persepsi siswa. Karena itu subjek penelitian ini melibatkan siswa SMP Negeri se-Kota Tangerang Provinsi Banten, yang sebelumnya ditetapkan 3 (tiga) SMP Negeri sebagai populasi terjangkau. Metode pengumpulan data dilakukan melalui penyebaran kuesioner atau angket ke sejumlah siswa yang terpilih secara acak sebagai sampel yang jumlahnya ditetapkan melalui rumus Slovin.

Penelitian ini berupa variabel tunggal, yaitu tentang kepemimpinan etis guru dalam pendidikan karakter di sekolah. Variabel tersebut secara konseptual diartikan sebagai tingkah laku guru dalam menstimulasi, memfasilitasi dan mengarahkan siswa atau sejumlah siswa dalam suatu tindakan pembelajaran untuk mencapai tujuan pendidikan yang komprehensif seraya berpijak pada nilai-nilai etika atau moral sehingga dapat mendatangkan kebaikan bersama.

Kepemimpinan etis guru dalam penelitian ini secara operasional mengacu pada aspek-aspek kepemimpinan transformasional sebagai berikut:

1. Kharisma atau pengaruh idealitas guru bagi siswa.

2. Motivasi inspirasional guru bagi siswa.

3. Perangsangan intelektual guru bagi siswa.

4. Perhatian individual guru bagi siswa.

Adapun langkah-langkah analisis data dalam penelitian ini dilakukan sebagai berikut :

1. Menghitung Persentase (\%) Skor Capaian Responden
Untuk mengkaji permasalahan dalam penelitian ini maka dilakukan pengolahan data hasil skor capaian responden yang didasarkan pada hasil dari masing-masing item pertanyaan untuk setiap indikator dengan formulasi rumus persentase yang dikemukakan oleh Purwanto (1991:113) sebagai berikut :

$$
P_{r}=\frac{F}{N} \times 100 \%
$$

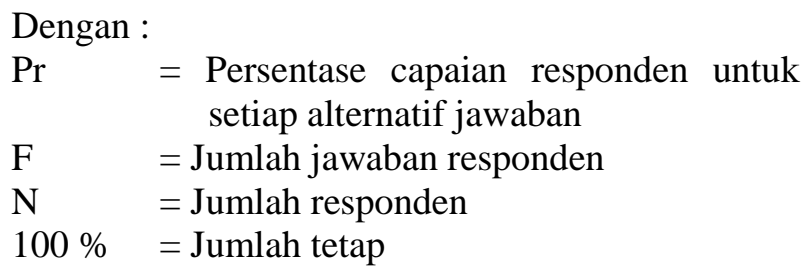

Selanjutnya capaian tersebut diakumulasikan untuk menetukan skor bagi setiap aspek atau indikator, kemudian skor setiap indikator diakumulasikan lagi untuk menetukan skor total variabel yang diteliti atau untuk menjawab permasalahan penelitian, yaitu tentang kepemimpinan etis guru dalam pendidikan karakter.

Menentukan skor setiap indikator dengan memakai formulasi rumus persentase yang dikemukakan oleh Sugiyono (2010:117) sebagai berikut:

$$
P_{r}=\frac{S C}{S I} \times 100 \%
$$

Dengan :

$\mathrm{Pr} \quad=$ Persentase capaian skor tiap indikator

$\mathrm{SC}=$ Jumlah skor capaian yang ada pada tiap butir soal

SI = Jumlah skor ideal (jumlah responden yang dikalikan dengan jumlah tertinggi pada alternatif jawaban

$100 \%=$ Jumlah tetap

2. Mengkonfirmasikan persentase (\%) skor capaian responden dengan kriteria/standar keberhasilan.

Setelah jawaban dianalisis melalui rumus di atas, selanjutnya dicocokkan atau sesuaikan dengan kualifikasi/kriteria yang diadaptasi dari Sugiyono (2010 : 107), seperti pada table 1 berikut. 
Tabel 1. Status Jawaban Responden

\begin{tabular}{ccc}
\hline No. & Rentang Status Skor & Kualifikasi/Kriteria \\
\hline 1 & $81-100$ & Sangat baik/Sangat Tinggi \\
\hline 2 & $61-80$ & Baik/Tinggi \\
\hline 3 & $41-60$ & Cukup/Sedang \\
\hline 4 & $21-40$ & Kurang baik/Rendah \\
\hline 5 & $0-20$ & Tidak baik/Sangat Rendah \\
\hline
\end{tabular}

Penelitian ini merupakan penelitian evaluatif. Penelitian evaluatif yang dilakukan peneliti termasuk jenis penelitian evaluatif kinerja sumber daya manusia. Penelitian ini bertujuan untuk melaksanakan evaluasi dan menggambarkan data yang berupa keterangan dan pernyataan yang ada tentang kinerja guru bersertifikasi. Penelitian dilakukan terhadap 5 (lima) orang guru kelas VII bersertifikasi yang bekerja di SMP Negeri 3 Salatiga.

Pendekatan penelitian yang digunakan adalah pendekatan kuantitatif sederhana dan kualitatif. Pendekatan kuantitatif menggunakan teknik pengumpulan data berupa angket dan observasi dengan instrument kuesioner dan Rubrik Penilaian Kinerja Guru yang merupakan terjemahan dari rubrik penilaian kinerja guru Model Charlotte Danielson. Selanjutnya untuk mencek dan memperbaiki kebenaran data dari kuesioner tersebut dilakukan pengumpulan data kualitatif dengan teknik wawancara dan studi dokumen.

\section{HASIL DAN PEMBAHASAN}

Setelah dilakukan penghitungan skor untuk masing-masing responden pada tiap item pertanyaan dalam angket, selanjutnya diakumulasikan untuk menentukan skor bagi setiap sub indikator. Berdasarkan pada hasil perhitungan setiap sub indikator tersebut, selanjutnya diakumulasikan untuk memperoleh data tiap indikator, yang hasilnya dapat dilihat pada table 2.

Berdasarkan data 2 dapat ditafsirkan, bahwa kondisi kepemimpinan etis guru dalam pendidikan karaker di sekolah pada tiap indikator rata-rata ada pada kategori sedang/cukup baik. Pada indikator kharisma atau pengaruh idealitas guru bagi siswa kondisinya ada pada $60,30 \%$ atau termasuk kategori sedang/cukup baik. Pada indikator motivasi inspirasional guru bagi siswa, kondisinya ada pada $61,21 \%$ atau lebih dekat ke kondisi sedang/cukup baik. Pada indikator perangsangan intelektual guru bagi siswa, kondisinya ada pada $59,22 \%$ atau termasuk kategori sedang/cukup baik. Pada indikator Perhatian individual guru bagi siswa, kondisinya ada pada 59,87\% atau termasuk kategori sedang/ukup baik.

Berdasarkan pada hasil penghitungan tiap indikator di atas, selanjutnya diakumulasikan sebagai kondisi kepemimpinan etis guru dalam pendidikan karakter di sekolah khususnya di SMP Negeri Kota Tangerang. Adapun akumulasi penghitungan seluruh indikator adalah sebagai berikut.

Tabel 2. Kondisi Kepemimpinan Etis Guru dalam Pendidikan Karakter di Sekolah Tiap Indikator

\begin{tabular}{lllc}
\hline \multicolumn{1}{c}{ Indikator } & $\begin{array}{c}\text { Skor } \\
\text { Total }\end{array}$ & $\begin{array}{c}\text { Rata-rata } \\
\text { Skor }\end{array}$ & \% \\
\hline $\begin{array}{l}\text { Pengaruh idealitas guru } \\
\text { bagi siswa }\end{array}$ & 1628 & 3,01 & 60,30 \\
\hline $\begin{array}{l}\text { Motivasi inspirasional } \\
\text { guru bagi siswa }\end{array}$ & 1928 & 3,06 & 61,21 \\
\hline $\begin{array}{l}\text { Perangsangan intelektual } \\
\text { guru bagi siswa }\end{array}$ & 1599 & 2,96 & 59,22 \\
\hline $\begin{array}{l}\text { Perhatian individual guru } \\
\text { bagi siswa }\end{array}$ & 1347 & 2,99 & 59,87 \\
\hline
\end{tabular}


Persentase capaian $=\frac{6502}{10800} \times 100 \%=60,20 \%$ dibulatkan menjadi $60 \%$

Berdasarkan pada hasil penghitungan di atas diketahui bahwa kondisi kepemimpinan etis guru dalam pendidikan karakter di SMP Negeri Kota Tangerang sebesar 60\% atau ada pada kategori sedang/cukup baik. Data hasil penelitian tersebut menunjukkan, bahwa kepemimpinan etis guru dalam pendidikan karakter siswa di sekolah, khususnya di SMP Negeri Kota Tangerang ada pada kategori sedang atau cukup. Hal tersebut berarti belum menunjukkan kondisi yang prima untuk mensukseskan pelaksanaan pendidikan karakter siswa di sekolah. Sebagaimana ditemukan oleh Amanchukwu, Stanley, \& Ololube dalam Hidayat \& Patras (2018) bahwa "kepemimpinan pendidikan yang efektif yaitu mampu memberikan visi ke depan (visionary), memiliki gairah dan semangat yang tinggi (passionate), kreatif, fleksibel, menginspirasi, inovatif, berani, dan mengeksperimen imajinasi untuk memulai perubahan"

Hasil yang pertama ini memberikan informasi bahwa idealitas guru dalam praktek pembelajaran sangat diperlukan. Idealitas guru yang dimaksud sebagaimana yang tertuang dalam Undang-Undang Undang Nomor 20 Tahun 2003 Pasal 40 Ayat 2, dinyatakan bahwa kewajiban pendidik adalah : (1) menciptakan suasana pendidikan yang bermakna, menyenangkan, kreatif, dinamis, dan dialogis; (2) mempunyai komitmen secara profesional untuk meningkatkan mutu pendidikan; dan (3) memberi teladan dan menjaga nama baik lembaga, profesi, dan kedudukan sesuai dengan kepercayaan yang diberikan kepadanya.

Idealitas guru bagi siswa merupakan inti dari kepemimpinan etis, yakni perwujudan nilai-nilai, kepercayaan-kepercayaan dan moral oleh pemimpin itu sendiri. Sementara inti dari pendidikan karakter adalah 'keteladanan'. Apa yang diteladankan? Tentu yang diteladankan adalah sikap, perilaku, gaya hidup yang sesuai dengan kaidah-kaidah moral yang berlaku atau sesuai dengan pertimbangan-pertimbangan baik-buruk, benar-salah, atau boleh-tidaknya suatu sikap atau tindakan yang diambil. Untuk itu kepemimpinan etis guru di sekolah menjadi faktor determinan dalam pendidikan karakter, sehingga dalam menjalankan tugasnya, guru harus berorientasi pada penghayatan dan perwujudan nilai-nilai moral.

Guru perlu menjadi motivasional inspirasi bagi siswanya. Dukungan ini paling tinggi dibandingkan aspek lainnya, yakni $61,21 \%$. Pengajaran yang menginspirasi membakar imajinasi melalui kombinasi tantangan intelektual, harapan tinggi dan rasa saling percaya antara guru dan pelajar yang mengundang pelajar untuk bergabung dengan guru dalam sebuah proses perjalanan penemuan (Blaylock, et. al., 2016).

Motiviasi inspirasional dari guru ini mendorong tumbuhnya karakter pada diri siswa yang bernilai (value) untuk pengembangan masa depan mereka, mengapa mereka perlu memperoleh pendidikan? Atau bagaimana seharusnya mereka bersikap? Karena guru guru merupakan sosok yang memiliki kedudukan penting bagi perkembangan potensi siswa (Slameto, Hardini, Prasetyo \& Indarini, 2018). Hal ini penting bagi seorang guru yang menjadi pemimpin etis. Seperti yang dikemukaan oleh Northouse (2013), bahwa guru yang mejadi seorang pemimpin etis, perlu memberikan pertanyaan-pertanyaan yang harus dijawab oleh nurani kita, yakni:

- Is this the right and fair thing to do?

- Is this what a good person would do?

- Am I respectful to others?

- Do I treat others generously?

- Am I honest toward others?

- Am I serving the community?

Merujuk kepada beberapa pendapat di atas dapat disimpulkan, kepemimpinan etis guru adalah bentuk perilaku yang dengan dukungan legalitas dan moralitasnya mampu 
mempengaruhi aktivitas belajar dan perkembangan kepribadian siswa sehingga dapat mewujudkan tujuan pendidikan dan pembelajaran yang komprehensif, sehingga dapat mendatangkan kebaikan bersama.

Atas dasar itu, guru sebagai pendidik dituntut untuk memiliki sikap dan perilaku kepemimpinan etis yang prima sehingga mampu menjadi agen moral di sekolah dan dapat menginternalisasikan nilai-nilai moral terhadap siswa yang diasuhnya, Dalam hal ini nilai moralitas kepemiminan guru lebih penting dari pada kecerdasannya dalam mengajar, karena produk pendidikan yang utama adalah terbentuknya moralitas peserta didik. Martin Luther King yang dikutip Muslich (2011:75) menyatakan, "Intelligence plus character ...that is the goal of true education". Ini berarti, keberhasilan pendidikan tidak dapat diukur secara parsial dari aspek kecerdasan semata, melainkan harus secara utuh dengan mempertimbangkan aspek perkembangan karakternya. Bahkan Theodore Roosevelt dalam Putra (tt), mengingatkan, "To educate a person in mind and not in morals is to educate a menace to society".

Pemimpin yang inspirasional oleh Bass dan Avolio dalam Yukl (2005:296) diartikan sebagai "sejauh mana seorang pemimpin mampu mengkomunikasikan suatu visi yang menarik, mampu menggunakan simbol-simbol untuk memfokuskan usaha pengikut dan memodelkan perilaku yang sesuai." Pemimpin yang inspirasional mampu memberikan visivisi tentang apa yang mungkin dan bagaimana memperolehnya. Pemimpin mampu meningkatkan makna dan mempromosikan harapan-harapan positif tentang kebutuhankebutuhan yang harus dikerjakan. Perilaku pemimpin inspirasional menurut Yukl (2005:297), “dapat merangsang antusiaisme bawahan terhadap tugas-tugas kelompok dan mengatakan hal-hal yang menimbulkan kepercayaan terhadap kemampuannya untuk menyelesaikan tugas dan mencapai tujuan kelompok."

Temuan ketiga dari hasil penelitian ini adalah tingginya harapan siswa bahwa guru sebagai perangsang intelektual bagi siswa. Hasil analisis data menujukkan kurangnya perangsangan intelektual guru pada siswanya. Padaha sudah lajim dipahami bahwa guru harus memiliki kompetensi professional, yakni mampu dalam bidang yang diajarkannya. Namun dalam kepemimpinan etis itu bukan hanya transfer of knowledge, tetapi guru sebagai role model seorang intelektual. Artinya guru harus bersikap sebagaimana seorang akademisi yang menggunakan nalar rasional dalam bersikap dan berperilaku.

Kepemimpinan etis guru dalam kemampuan perangsang intelektual dipandang mampu meningkatan karakter bagi siswa dalam bentuk motivasi belajar. Hasil ini memperkuat temuan Taunu \& Iriani (2019) bahwa program penguatan pendidikan karakter membawa pengaruh yang positif dalam prestasi maupun perilaku peserta didik di sekolah. Dengan pendidikan karakter tersebut peserta didik lebih berprestasi. Dengan demikian, seorang guru perlu memberikan penguatan intelektual dalam bidangnya, sehingga menjadi sosok teladan layaknya seorang ilmuan dimata para siswanya.

Kepemimipan etis dari sisi intelektual mampu memberikan kesadaran bagi angggotanya, siswa, dalam peningkatan kreativitas menyelesaikan masalah sebagai bentuk kepedulian guru terhadap siswanya. Yukl (2005:297) mengungkapkan, bahwa "stimulasi intelektual dipahami dalam upaya seorang pemimpin meningkatkan kesadaran anggota terhadap persoalan-persoalan anggota dan mempengaruhi anggota untuk melihat persoalan tersebut melalui perspektif baru." Terkait hal ini, pemimpin melalui pemberian stimulasi intelektual merangsang kreativitas anggota dan mendorong untuk menemukan solusi bagi pemecahan masalah yang dihadapi dengan prespektif baru. Menurut Deluga dalam 
Yukl (2005:297) bahwa melalui pendekatan ini pengikut didorong untuk berpikir mengenai relevansi cara, sistem nilai, kepercayaan, harapan dan bentuk organisasi yang ada saat ini. Anggota juga didorong melakukan inovasi dalam menyelesaikan persoalan dan berkreasi untuk mengembangkan kemampuan diri, serta didorong untuk menetapkan tujuan atau sasaran yang menantang..

Atas dasar itu, maka kepemimpinan etis guru menjadi faktor diterminan untuk keberhasilan pelaksanaan pendidikan karakter di sekolah. Sebaik apapun konsep kurikulum pendidikan karakter akan tidak bermakna, jika tidak didukung oleh kualitas kepemimpinan etis guru di sekolah.

Ini sejalan dengan Vaughan dan Hogg yang dikutif Sujanto (2007:67) yang menjelaskan, "kepemimpinan adalah usaha menggerakkan orang lain untuk dapat mencapai tujuan bersama (kelompok)." Sedangkan Danim (2008 : 56) mengartikan, kepemimpinan adalah setiap tindakan yang dilakukan oleh individu atau kelompok untuk mengkoordinasi dan memberi arahan kepada individu atau kelompok lainnya yang tergabung dalam wadah tertentu untuk mencapai tujuan yang telah diterapkan sebelumnya."

Kedua pendapat di atas intinya sama, bahwa kepemimpinan merupakan perilaku seseorang yang berusaha mempengaruhi orang lain atau sekelompok orang dalam suatu ikatan tertentu untuk bekerja sama mencapai tujuan bersama. Ini seperti diungkapkan Gani, Setyamidjaya, dan Sumardi (2008:4), "kepemimpinan merupakan proses atau tindakan mempengaruhi orang lain di dalam kelompok agar mengerti, memahami dan terpanggil (commit) terhadap apa yang perlu dikerjakan dan bagaimana hal itu dapat dilakukan secara efektif, agar usaha bersama tersebut dapat mencapai tujuan".

Berdasarkan pada uraian di atas dapat disimpulkan, bahwa kepemimpinan sebagai perilaku atau tindakan seseorang yang karena kapasitasnya mampu mempengaruhi orang lain atau sekelompok orang dalam suatu ikatan tertentu untuk bersama-sama mencapai tujuan bersama.

Jelas tidak mudah untuk menjalankan kepemimpinan etis, karena kita sering terjebak dalam kesulitan dalam memberi makna "benar" terhadap sesuatu. Padahal kepemimpinan etis memiliki dua peran yakni memutuskan dengan benar secara etis dan memimpin dengan sikap dan perilaku benar secara etis dalam berinteraksi dengan pengukutnya.

Kepemimpinan sejatinya harus mewujudkan kebaikan bersama, karena itu penyertaan nilai etika atau nilai moral dalam pengambilan keputusan merupakan hal yang urgen bagi pemimpin. Kepemimpinan bukan sekedar kekuasaan, tetapi juga kepercayaan para pengikut, Kepemimpinan etis yang mempertimbangkan kebaikan bersama akan memperoleh kepercayaan pengikut dan ini menjadi modal sosial bagi upaya-upaya kepemimpinannya. Menuurut Trevino, et. al. (2003:37), "Leaders who are ethical demonstrate a level of integrity that is important for stimulating a sense of leader trustworthiness, which is important for followers to accept the vision of the leader.".

Burns mengungkapkan kepemimpinan etis melalui gagasannya tentang kepemimpinan transformasional. Menurut Burns (1978:20) bahwa "kepemimpinan transformasional sebagai sebuah proses dimana para pemimpin dan pengikut saling menaikkan diri ke tingkat moralitas dan motivasi yang lebih tinggi. Para pemimpin tersebut mencoba menimbulkan kesadaran para pengikut dengan menyerukan cita-cita yang lebih tinggi dan nilai-nilai moral seperti kemerdekaan, keadilan dan kemanusiaan, bukan didasarkan atas emosi".

Ciri dari perilaku kepemimpinan etis sangat peduli terhadap apa yang dibutuhkan dan kehendak pengikutnya dan berupaya membantu mereka mencapai kemampuan dan hasil terbaiknya. Burns (1978:20) mengungkapkan, 
bahwa: "Mahatma Gandhi sebagai contoh klasik kepemimpinan tranformasional. Gandhi menimbulkan harapan dan permintaan dari jutaan rakyatnya dan dalam proses itu digantikan oleh dirinya sendiri."

Burns (1978) dalam pemikirannya memang tidak secara tegas mendefinisikan konsep kepemimpinan etis. Tetapi Burns sadar akan pentingnya nilai-nilai moral dalam menjalankan fungsi kepemimpinan dan membantu secara bijak dalam mengatasi berbagai pertentangan antar nilai yang ada. Karena dalam setiap praktek kepemimpinan harus menjaga komitmen untuk saling mengingatkan tentang pentingnya moralitas dan saling memberi motivasi. Namun demikian inisiatif perilaku bermoral harus datang dari pemimpin untuk mewujudkan keadilan, kesejahteraan, kedamaian, kesetaraan, dan aspek-aspek kemanusiaan lainnya. Suasana kepemimpinan seperti itu akan mendorong pengikut melakukan perbaikan dari hari ke hari untuk menjadi yang lebih baik.

Hasil keempat dari penelitian adalah pentingnya perhatian individual guru bagi siswa. Dari data yang diperoleh atensi guru secara indivual dapat dikatakan belum cukup. Hal ini terlihat dari respon siswa yang di bawah $60 \%$ atau tepatnya $59,87 \%$ yang berkategori cukup. Atensi atau perhatian guru terhadap siswa ini pengaruhnya sangat kuat dalam diri siswa baik melalui kontak mata, mendesis, gerakan tangan yang dapat mnedorong pergatoan, disiplin, partisipasi serta keantusiasan siswa dalam belajar (Purwanti, Salijah \& Dollah, 2017). Lebih lanjut hasil penelitian dari Riley, McKevitt, Shriver \& Allen (2011) dalam studinya menunjukkan bahwa jadwal perhatian guru dalam waktu yang tetap efektif dalam meningkatkan perilaku ontask siswa dan mengurangi perilaku off-task mereka.

Hasil penelitan Riley, McKevitt, Shriver \& Allen di atas juga merekomendasikan bahwa seorag guru yang professional hendaknya memiliki adanya jadwal waktu tepat kapan pemberian atensi ini diberikan kepada siswa, bahkan sekolah seharusnya melakukan intervensi pada guru agar dapat memiliki fixe time schedule dalam pemberian atensi pada siswanya.

Hasil di atas dapat memberikan sebuah inspirasi baru bahwa kepemimpinan tidak hanya dimiliki oleh kepala sekolah, tetapi guru juga wajib memiliki kepemimpinan, dalam hal ini adalah kepemimpinan etis.

\section{SIMPULAN}

Berdasarkan paparan hasil penelitian diperoleh kesimpulan bahwa kepemimpinan etis guru dalam pendidikan karakter siswa di SMP Negeri Tangerang belum menunjukkan kondisi yang dapat dibanggakan. Hal ini seperti terungkap dalam data tiap aspek kepemimpinan etis, yang meliputi kharisma atau pengaruh idealitas guru bagi peserta didik, kondisinya ada pada $60,30 \%$ atau termasuk kategori sedang/cukup. motivasi inspirasional guru bagi peserta didik, kondisinya ada pada $61,21 \%$ atau termasuk kategori yang lebih dekat ke kondisi cukup/sedang. Perangsangan intelektual guru bagi peserta didik, kondisinya ada pada 59,22\% atau termasuk kategori cukup/sedang. Perhatian individual guru bagi peserta didik, kondisinya ada pada $59,87 \%$ atau termasuk kategori cukup/sedang.

Temuan-temuan di atas menunjukkan, bahwa kepemimpinan etis guru dalam pendidikan karakter siswa, khususnya di SMP Negeri Kota Tangerang, belum atau dapat dibanggakan, karena masih ada dalam kondisi biasa-biasa saja atau sedang. Ini berarti untuk mewujudkan kondisi kepemimpinan etis guru yang sangat baik, perlu ada pembinaan dari pihak terkait.

\section{DAFTAR PUSTAKA}

Anugraheni, I. (2017). Analisa Faktor-Faktor yang Mempengaruhi Proses Belajar Guru-Guru Sekolah Dasar. Kelola: 
Jurnal Manajemen Pendidikan, Vol. 4, No. 2, Juli-Desember 2017. DOI: https://doi.org/10.24246/j.jk.2017 .v4.i2.p205-212. Tersedia: https://ejournal.uksw.edu/kelola/article/ view/1297

Blaylock, M., Churches, R., Gowers, F., Mackenzie, N., McCauley,D. and Pye, M., (2016). Inspiring teachers: how teachers inspire learners. Berkshire RG1 4RU: Education Development Trust.

Burns, J. M. (1978). Leadership. New York : Harper \& Row.

Danim, S. (2008). Motivasi Kepemimpinan dan Efektivitas Kelompok. Bandung: Penerbit Rineka Cipta.

Gani, S. D., Setyamidjaya, Dj. dan Sumardi. (2007). Landasan Teori Manajemen Pendidikan, Bogor: Program Pascasarjana Universitas Pakuan

Hidayat, R. \& Patras,Y. E. (2018). Pemetaan Jenis, Indikator dan Kegunaan Kepemimpinan Pendidikan: Kajian Literatur dari Situs Indonesian Publication Index (IPI). Kelola: Jurnal Manajemen Pendidikan. Vol. 5, No. 2. 124 - 138. DOI: https://doi.org/ 10.24246/j.jk.2018.v5.i2.p124-138.

Tersedia: https://ejournal.uksw.edu/ kelola/article/view/2029.

Leithwood, K., Louis, K. S., Anderson, S. \& and Wahlstrom, K. (2004). How leadership influences student learning. Minnisotta, Toronto: The Wallace Foundation.

Moore, H. L., Latimer, R. M. \& Villate, V. M. (2016), The Essence of Teacher Leadership: A Phenomenological Inquiry of Professional Growth. International Journal of Teacher Leadership. Vol. 7, No. 1.
Muslich, M. (2011), Pendidikan Karakter; Menjawab Tantangan Krisis Multidimensional, Jakarta: Bumi Aksara

Nerlino, E. (2020). A theoretical grounding of teacher leadership. Journal of Professional Capital and Community. Volume 5 Issue 2.

Northouse, P. G. (2013). Leadership: Theory and practice (6th ed.). Thousand Oaks, CA: Sage

Putra, M. G. B. A (tt) dalam (http://pks. psikologi.unair.ac.id/ coretan -kami/ membangun-peradaban-bangsadengan-pendidikan-berkaraktermoral/diunduh tanggal 14-8-2019, pukul 13.00)

Purwanto, N. (1991). Prinsip-Prinsip dan Teknik Evaluasi Pembelajaran. Bandung: Remaja Rosdakarya..

Purwanti, E., Salijah, K. \& Dollah, S. (2017). Teachers' Strategies in Getting Students' Attention During Transition in EFL Classroom (A Case Study on English Teacher in a Junior High School). Tersedia: http://eprints.unm.ac.id/6804/1/ARTIK EL.pdf

Riley, J. L., McKevitt, B. C., Shriver, M. D. \& Allen,K. D. (2011). Increasing on-task behavior using teacher attention delivered on a fixed-time schedule. Journal of Behavioral Education. Vol. 20, No. 3149 - 162. Tersedia: https://www.researchgate.net/publicatio n/225774669_Increasing_On-

Task_Behavior_Using_Teacher_Attent ion_Delivered_on_a_Fixed-

Time_Schedule

Slameto, Hardini, A. T. S., Prasetyo T. \& Indarini, E. (2018). Peningkatan disiplin Guru SD melalui Pelatihan Partisipatif Model In - On. Kelola: Jurnal Manajemen 
Pendidikan. Vol 5. No.1, hal 47 - 54. DOI: https://doi.org/10.24246/j.jk.2018 .v5.i1.p47-54. Tersedia: https://ejournal.uksw.edu/kelola/article/ view/1693

Sugiyono. 2010. Metode Penelitian Pendidikan Pendekatan Kuantitatif, kualitatif, dan $R \& D$. Bandung: Alfabeta

Sujanto, B. (2007). Manajemen Pendidikan Berbasis Sekolah, Jakarta:Sagung Seto.

Taunu, E. S. H \& Iriani, A. (2019). Evaluasi Program Penguatan Pendidikan Karakter Terintegrasi Mata Pelajaran Matematika di SMP Negeri. Kelola. Jurnal Manajemen Pendidikan. Vol. 6, No. $\quad 1 . \quad 64 \quad-\quad 73$. DOI: https://doi.org/10.24246/j.jk.2019.v6.i1 .p64-73.

Tersedia: https://ejournal.uksw.edu/kelola/article/ view/1777

Trevino, L. K., Brown M., \& Hartman, L.P. (2003). A qualitative investigation of perceived executive ethical leadership: Perceptions from inside and outside the executive suite. Human Relations, 56(1), 5-37.

Yukl, G. (2005), Kepemimpinan dalam Organisasi, Terjemahan, Jakarta: PT. Indeks.

Harris, A. \& Jones, M. (2019), Teacher leadership and educational change. Journal School Leadership \& Management Formerly School Organisation. Vol. 39. 